\title{
Desenvolvimento de foguetes de baixa altitude para auxiliar no ensino
}

\author{
Ana Carolina Luciani Corrêa \\ Edson Luiz Zuchi \\ Maria Julia Fischer \\ Daniel Veloso Batschauer \\ Mateus Muller Ribeiro \\ gfig.ifsc@gmail.com
}

GFIG - Grupo de Foguetes do IFSC Gaspar

\author{
Leonardo Ronald Perin Rauta \\ Maurício Justino \\ leonardo.rauta@ifsc.edu.br \\ mauricio.justino@ifsc.edu.br \\ GFIG - Grupo de Foguetes do IFSC Gaspar \\ Instituto Federal de Santa Catarina - Câmpus Gaspar \\ Gaspar, Santa Catarina
}

\begin{abstract}
Foguete

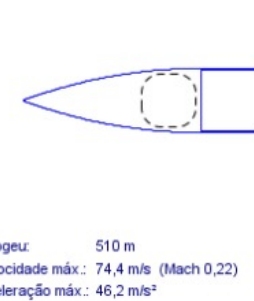

Aceleraçăo máx.: $46,2 \mathrm{~m} / \mathrm{s}^{2}$ o Centro de Pressão e o Centro de Gravidade do foguete, respectivamente.

\section{RESUMO}

Durante a Guerra Fria (pós Segunda Guerra Mundial - 1947 a 1991) ficou evidente o interesse das grandes potências mundiais na exploração espacial. Desde então muitas pesquisas e agências espaciais foram criadas com o objetivo de realizar essa exploração. No entanto, essas pesquisas ficaram restritas apenas aos países e instituições que possuíam grande capacidade financeira e tecnológica. Naquela época existia, e ainda hoje existe, pouca pesquisa para desenvolver foguetes de baixa altitude, sem despender grande volume financeiro. Assim, este trabalho apresenta o desenvolvimento de um foguete de baixa altitude, criado para incentivar e demonstrar para estudantes do ensino fundamental que o lançamento de foguetes não precisa ficar restrito apenas à grandes empresas e agências espaciais, que mesmo em cidades pequenas, eles podem presenciar e experimentar um lançamento de foguete, claro, dada as devidas proporções.
\end{abstract}

Figura 1: Foguete projetado no software OpenRocket. Da esquerda para direita, capsula, compartimento de eletrônica, compartimento de experimentos, carga de ejeção do paraquedas, paraquedas, motor e aletas. Os pontos vermelho e azul indicam

\section{KEYWORDS}

Foguete, Sistemas embarcados, Foguete-modelismo, Aeroespacial

\section{INTRODUÇÃO}

O uso e lançamento de foguetes vem aumentando nos últimos anos. Em 2018 a China enviou uma missão para estudar o lado escuro da Lua e até hoje envia imagens inéditas sobre o lado que até então era desconhecido; e no mesmo ano a NASA enviou uma sonda à Marte. Em 2019 a Índia lança seu primeiro foguete; a China envia outra sonda para a Lua e esta, em 2020, retorna com $2 \mathrm{~kg}$ de rochas lunares [1]. Em 2020 a SpaceX se torna a primeira empresa privada a realizar uma missão tripulada à ISS (International Space Station); e a Rússia planeja retomar envio de missões de exploração à Vênus [2]. Essas são apenas algumas das diversas notícias que abordam o assunto de exploração espacial nos últimos anos.

Esse crescente aumento no número de lançamentos de foguetes demonstra o interesse nas riquezas inexploradas e desconhecidas que existem em outros planetas. Para incentivar e aumentar o interesse de estudantes para esta área, existem algumas iniciativas, como a Olimpíada Brasileira de Astronomia (OBA) e a Mostra Brasileira de Foguetes (MOBFOG) [3], o Festival Brasileiro de Minifoguetes [4], a Latin America Space Challenge (LASC) [5] entre outros eventos e festivais, nacionais e internacionais voltados a essa área. Essas iniciativas visam o desenvolvimento de foguetes e premiação dos foguetes que cumprirem os desafios propostos. A maioria dos desafios é que o foguete alcance um apogeu máximo, mas existem desafios de aterrissar mais próximo de um alvo ou atingir a maior distância.

Para efetuar as correções necessárias no foguete e também para estimar o quão próximo do objetivo o foguete chegou, é necessário coletar informações a respeito do comportamento do foguete no ar. Esses dados possibilitam à equipe de desenvolvimento, identificar os pontos falhos para corrigi-los e até mesmo para reprojetar novos foguetes para que estes cheguem o mais próximo possível do objetivo.

Visando um melhor voo do foguete e redução dos coeficientes de arrasto e forças exercidas sobre ele, é fundamental que a comunicação da telemetria seja sem fio. Assim, esse projeto visa o desenvolvimento de foguetes com apogeu de 500 metros a $1 \mathrm{~km}$ 
que pode ser utilizado para demonstração de lançamento para a comunidade. Assim, esse trabalho apresenta o desenvolvimento de um foguete de baixa altitude (Figura 1), com foco na eletrônica embarcada desse foguete, também chamada de aviônica.

\section{FUNDAMENTAÇÃO TEÓRICA}

No projeto de dispositivos aeroespaciais existem algumas áreas, as quais têm como objetivo, o desenvolvimento de uma parte desse dispositivo. Vale destacar as áreas de moto-propulsão - estuda o projeto do motor e combustíveis utilizados; estrutura e estabilidade - estuda o formato da aeronave e a distribuição das forças exercidas sobre ela; e a aviônica - que é a área responsável pelos equipamentos eletrônicos utilizados dentro da aeronave [6].

A aquisição desses dados é dada pela eletrônica embarcada no foguete (aviônica) e, para esse tipo de aquisição de informações, tem-se o nome de telemetria. Embora a telemetria nem sempre seja necessária em dispositivos aeroespaciais devido, em sua maioria das vezes, a existência de um humano para controle desta, ela é fundamental para aeronaves não tripuladas, em que é necessário identificar informações do voo em tempo real [7]. Para que esta telemetria seja funcional, é necessário que exista uma comunicação entre a estação/base em terra e o foguete lançado.

A comunicação com foguetes deve ser realizada por um meio sem fio. Para isso, existem diversos protocolos de redes sem fio que podem ser utilizadas para essa finalidade, como por exemplo, rede Wi-fi, Bluetooth, ZigBee e LoRaWan. No entanto, a rede Wi-fi acaba tendo uma limitação de transmissão de cerca de 100 metros (sem amplificação), a rede Bluetooth possui uma limitação de aproximadamente 50 metros.

Conforme estudo apresentado por [8], a rede LoRa possui uma menor perda de pacotes e uma melhor eficiência em comparação à rede ZigBee e outras redes. Possibilitando assim a verificação da eficácia do desenvolvimento de um sistema de comunicação com foguetes utilizando esses tipos de rede.

Ainda, devido a diversos problemas que podem ocorrer durante o lançamento do foguete, como explosão, queima [9] e até mesmo desvio da rota de subida e sem possibilidade de recuperação (queda na água, por exemplo), é comum ter redundância, muitas vezes com a replicação do mesmo sistema. O sistema apresentado nesse trabalho contempla dois subsistemas, um utilizado embarcado no foguete, realizando a captura dos dados telemétricos; e outro em terra, para recebimento dos dados que estão sendo capturados durante o voo.

\section{METODOLOGIA}

No trabalho aqui apresentado foi adotada uma metodologia de caráter exploratório, pois teve como objetivo o desenvolvimento de um sistema/equipamento para verificar a viabilidade de seu uso. Para tal, foram adotadas as seguintes etapas de desenvolvimento do foguete, estando apenas a etapa de desenvolvimento da aviônica com subetapas: (1) projetar e desenvolver um motor que forneça a energia necessária para colocar o foguete o mais próximo possível do apogeu estipulado (500 m a $1 \mathrm{~km}$ ); (2) determinar e produzir combustível para uso no propelente do foguete - normalmente utilizado um composto de $65 \%$ nitrato de potássio e $35 \%$ de combustível (sacarose, sorbitol, dextrose); (3) projetar e confeccionar a fuselagem do foguete em fibra de vidro - a fuselagem, também conhecida como corpo do foguete, deve abrigar em seu interior o motor, a aviônica, o payload (espaço para carregar carga no foguete - geralmente experimentos) o paraquedas e sistema de ejeção; (4) projetar e confeccionar as aletas e ogivas do modelo; (5) projetar e montar a aviônica do foguete; (5.1) desenvolver o sistema de comunicação do foguete; (5.2) desenvolver a estação em terra para comunicação com o foguete; (5.3) desenvolver um sistema para ejeção do paraquedas; (6) confeccionar o paraquedas; (7) realizar testes em bancada da aviônica; (8) integração do foguete; (9) realizar testes de voo.

Infelizmente devido às restrições impostas para tentar combater o Covid-19, as etapas 8 e 9, integração e teste de voo, não foram realizadas por não ser permitida aglomeração de pessoas. Como o projeto é desenvolvido por estudantes de ensino médio, é necessário que os integrantes de cada um das áreas do foguete (aviônica, motor, etc.) estivessem presentes para a integração destas no foguete, além de ser um requisito para realização do teste de voo.

\section{DESCRIÇÃO DO FOGUETE DESENVOLVIDO}

Conforme descrito por [6], o projeto de desenvolvimento de um foguete pode ser dividido em áreas, pois assim é possível agrupar os conhecimentos e especialistas em determinado assunto para que o produto desenvolvido seja o mais adequado ao projeto. Assim, o foguete desenvolvido nesse trabalho foi dividido nas áreas (subsistemas) de, estrutura e aerodinâmica, propulsão (motor e combustível), recuperação e, aviônica.

O foguete foi projetado para atingir um apogeu (altura máxima acima do solo) de 500 metros. Nas simulações realizadas no software de projeto e simulação, OpenRocket, foi obtido um apogeu estimado de 510 metros (Figura 1), dentro do esperado. Por se tratar de um apogeu simulado, o foguete pode atingir uma altitude, tanto maior, quanto menor da qual foi estimada.

\subsection{Estrutura e aerodinâmica}

O projeto estrutural e aerodinâmico do foguete conta com três partes principais, a capsula, o corpo de carga e o corpo de motor. Todas essas partes foram unidas por tubos de PVC, o que permitiu a fixação de todas essas partes na estrutura do foguete.

A capsula geralmente é o local em que ficam a tripulação ou elementos sensíveis da missão espacial, além de ser responsável também pelo primeiro contato do foguete com o ar, quando está em movimento. No caso do foguete projetado, a capsula apenas tem o objetivo de reduzir o coeficiente de arrasto do foguete.

A capsula desse foguete foi desenvolvida utilizando uma taça descartável de espumante, preenchida com espuma expansiva. Foi utilizada essa taça por ser de material leve e também ser pontiaguda, conforme previa o projeto. Além disso, ela foi preenchida com espuma expansiva para evitar que, ao colidir com o solo, a capsula quebre e se rompa.

O corpo de carga do foguete é um compartimento utilizado para armazenar a carga que irá a bordo da missão, o computador de bordo do foguete (aviônica), e também o paraquedas - sistema de recuperação. Esse corpo possui um comprimento de 80 centímetros e um diâmetro de 5,4 centímetros. Ele foi feito com fibra de vidro e possui uma parede de espessura de $1,5 \mathrm{~mm}$.

Por fim, a última parte do foguete é o corpo de motor. Essa seção do foguete é responsável pelo acondicionamento do motor 
do foguete. Externamente essa seção é feita de fibra de vidro com espessura de $1,5 \mathrm{~mm}$ e um diâmetro externo de $5,4 \mathrm{~cm}$. Devido à diferença de diâmetros entre o diâmetro interno do tubo e o diâmetro externo do motor, foi necessário o desenvolvimento de um bloco de adaptação e fixação do motor, feito em MDF. Afixado no corpo de motor também encontram-se as aletas, responsáveis pela aerodinâmica de voo do foguete. As aletas possuem formato semielipsoidal e foram produzidas em material MDF.

Todo ancoramento do foguete é realizado por um cabo de aço. Esse cabo ancora desde o motor, o paraquedas, o corpo de carga, até a capsula. Isso permite que, ao ejetar o paraquedas, o foguete não se divida em diversos pedaços, mas sim, caia como uma unidade única. Toda a estrutura apresentada é prevista no projeto do foguete.

\subsection{Propulsão}

No subsistema de propulsão tem-se como principal objetivo projetar e construir um motor-foguete que possua o empuxo necessário para o foguete atingir o apogeu. Devido à existência de apenas um único fabricante de motores de propelente sólido no Brasil e, este fabricar apenas motores para foguetes pequenos (apogeu de 50, 100 metros), foi necessário o projeto e fabricação do motor, além de produzir o combustível - propelente.

O motor projetado foi desenvolvido em um tubo inox de $33 \mathrm{~mm}$ de diâmetro externo e $30 \mathrm{~mm}$ de diâmetro interno, com espessura de parede de $1,5 \mathrm{~mm}$. Nas extremidades do motor foi inserida uma tampa e uma tubeira - possui um orifício que permite a saída dos gases de combustão e, com essa saída dos gases, move o motor. Como a tampa e a tubeira são inseridas no tubo de inox, a câmara de combustão ficou com um comprimento de $195 \mathrm{~mm}$ com um diâmetro de $30 \mathrm{~mm}$, gerando um volume total de $134.303 \mathrm{~mm}^{3}$ $\left(134,3 \mathrm{~cm}^{3}\right)$. A Câmara de exaustão (tubeira), possui $91 \mathrm{~g}$ com a garganta de $9 \mathrm{~mm}$ de diâmetro. A massa do motor com tubeira, tampa e parafusos é de $465 \mathrm{~g}$ a massa de propelente é de $150 \mathrm{~g}$, perfazendo um total de $615 \mathrm{~g}$.

Já o combustível, também chamado de propelente, utilizado possui formulação de $65 \%$ de oxidante (nitrato de potássio) e $35 \%$ de combustível (sacarose), comumente chamado de KNSu. Esse tipo de combustível é utilizado em foguetes de baixa altitude.

\subsection{Recuperação}

O subsistema de recuperação é responsável por duas tarefas, trazer o foguete ao solo de maneira segura e, localizá-lo após a sua aterrissagem. O equipamento utilizado para a tarefa de aterrissagem segura foi o paraquedas. Para isso, foi projetado um único paraquedas de $80 \mathrm{~cm}$ de diâmetro com um total de 8 linhas com comprimento de $80 \mathrm{~cm}$. Segundo as simulações realizadas pelo software OpenRocket, isso faz com que o foguete tenha uma decida de aproximadamente 9,3 metros por segundo. O acionamento do paraquedas dá-se ao atingir o apogeu por um sistema de ejeção de paraquedas. Quando o apogeu é identificado, uma carga de explosivo é acionada e faz com que o foguete se abra em duas partes e o paraquedas seja expulso de dentro dele, abrindo-o e possibilitando uma queda lenta e segura. Já a tarefa de localização é encontrar, de forma visual, o foguete após seu contato com o solo. Por fazer parte da aviônica, esse sistema será melhor descrito naquele subsistema.

\subsection{Aviônica}

Embora o que mova o foguete seja o consumo do combustível no interior do motor e existam modos mecânicos para acionamento do paraquedas, o uso de um computador de bordo é de suma importância. Com um sistema eletrônico embarcado em um foguete, é possível controlar, automaticamente ou remotamente, o acionamento do paraquedas, informar o local em que o foguete pousou, realizar a telemetria desse foguete, avaliar experimentos embarcados, entre outras funções. A aviônica desenvolvida para esse projeto ficou responsável pela ejeção do paraquedas, comunicação para informar a localização do pouso do foguete e, telemetria do foguete.

Devido aos custos envolvidos e o tempo necessário para prototipação de um circuito específico para a aviônica, ela foi baseada em componentes já existentes no mercado (COTS - do inglês, Commercial Off-The-Shelf). Assim, ela foi baseada em Arduíno, com a placa UNO e, comunicação XBee, com os adaptadores para o Arduino UNO. Normalmente um foguete possui sistemas redundantes, neste apresentado não foi desenvolvida redundância na aviônica.

Com isso, para o módulo de ejeção de paraquedas foi utilizado: um Arduino UNO, um relé e um sensor BMP-280 (aferir a pressão atmosférica). O software desenvolvido para esse módulo da aviônica avalia a variação da pressão atmosférica - quanto mais alto, menor a pressão atmosférica - e, ao identificar um aumento na pressão, aciona o relé. O relé está ligado a um acionador eletrônico de fogos de artifícios (skib) e esse skib está inserido em uma carga explosiva. Ao ser acionado o relé, a carga explosiva faz com que o foguete se abra e ejete o paraquedas.

O sistema de telemetria faz uso do Arduino UNO e do sensor BMP-280. Devido ao fato do sensor BMP-280 aferir mais de uma informação - pressão atmosférica, temperatura ambiente e umidade - a telemetria faz essas aquisições e as encaminha para o sistema de comunicação. Embora a telemetria possua poucos dados coletados, ela é importante para identificar se essas grandezas físicas podem influenciar no voo do foguete.

Por fim, o sistema de comunicação. Para esse sistema, embora o trabalho de [8] apresente uma comparação entre o protocolo de comunicação LoRa e ZigBee, e apresente que o LoRa possui uma menor perda de pacotes, foi utilizado o protocolo XBee devido à disponibilidade de COTS para utilizar com Arduino. Assim, foram utilizados embarcados no foguete: um Arduino UNO e um módulo XBee Pro S2C. Para a comunicação poder ser realizada, foi desenvolvido um módulo para ser utilizado em terra, este módulo faz uso de: adaptador XBee Explorer USB e um computador.

No módulo embarcado no foguete, todas as informações lidas da telemetria e também do sistema de ejeção, são enviados para o sistema em terra. Isso permite que o sistema em terra tenha todas as informações do foguete em tempo real. Já o módulo em terra, apenas recebe as informações transmitidas e apresenta no console.

\section{TESTES}

Conforme já apresentado, não foi possível a realização do teste de voo por causa das restrições impostas à Covid-19. Assim, foram realizados apenas testes para cada uma das áreas do foguete, motor e combustível; paraquedas; e aviônica. Apenas a área de estrutura 
e aerodinâmica não teve teste físico, foi utilizado apenas simulador para avaliar se estava tudo adequado ao projetado.

\subsection{Testes motor e combustível}

No teste do combustível, foram produzidos alguns grãos propelentes (unidades de propelente sólido) e, para estes, foram realizados testes para avaliar a cor e duração da queima de cada um dos grãos. Para o motor, foram produzidos cinco grãos de propelente e inseridos no motor. Após o motor estar cheio de combustível, ele foi colocado em uma guia que permite o movimento unidimensional do motor e este foi encostado em uma célula de carga. Com isso, foi possível determinar qual o empuxo total e empuxo máximo produzido pelo motor, determinando assim sua classe. Esses testes foram realizados antes da pandemia.

\subsection{Testes paraquedas}

O teste de paraquedas foi realizado afixando uma massa próxima à estimada do foguete, cerca de $2 \mathrm{~kg}$, nas cordas do paraquedas. Após essa afixação, o paraquedas foi dobrado e lançado do segundo andar de um prédio. Com isso, foi possível estimar se o paraquedas possuía um tamanho adequado para abrir em tempo hábil para proteger a carga que foi ali afixada. Além disso, foi possível determinar também o tempo de queda de um objeto de $2 \mathrm{~kg}$ de uma altura estimada em cerca de 9 metros de altura. Teste também realizado antes da pandemia.

\subsection{Testes aviônica}

Como a aviônica possui alguns subsistemas, como sistema para ejeção do paraquedas, sistema de comunicação e sistema de telemetria; os testes foram realizados individualmente.

5.3.1 Ejeção do paraquedas. Para o sistema de ejeção foram realizados dois testes, (i) verificar se o sistema embarcado para identificação do apogeu estava funcionando e; (ii) determinar a carga de explosivo necessária para ejetar o paraquedas de dentro do corpo do foguete.

No primeiro teste do sistema de ejeção (i), verificar se o sistema embarcado identifica corretamente o apogeu, foi trocada a carga explosiva por um LED e esse sistema foi inserido dentro de um elevador. Após subir, pelo menos 5 metros (2 andares), o sistema teria que identificar quando o elevador invertesse seu sentido e ligar o LED. Isso demonstrava quando a carga explosiva seria acionada para liberação do paraquedas. Já no segundo teste (ii), determinar a carga explosiva necessária para ejeção do paraquedas, foi inserido um paraquedas no corpo do foguete e, testando diversas cargas explosivas. Utilizando $2 \mathrm{~g}$ de explosivo o corpo do foguete se rompia, com $1 \mathrm{~g}$ de explosivo não havia força suficiente para ejeção do paraquedas. Assim, chegou-se que $1,5 \mathrm{~g}$ de explosivo era suficiente para ejetar o paraquedas e essa carga não prejudicava a estrutura do corpo do foguete. Teste também realizados antes da pandemia.

5.3.2 Comunicação. O teste do sistema de comunicação foi realizado com o sistema do foguete e a estação em terra lado a lado e posteriormente a 50 metros, 100 metros, 150 metros e 200 metros entre os sistemas.

Nos testes, a comunicação ocorreu normalmente entre as placas e a taxa de perda de pacotes ficou em 0 pacotes perdidos de 100 pacotes enviados até 150 metros de distância. A uma distância de 200 metros entre os sistemas, a comunicação começou apresentar perda de pacotes. Nos testes realizados a essa distância, em média 9 pacotes eram perdidos, de um total de 100 pacotes. Assim, embora houvesse potência no sinal recebido no sistema em terra, não foram realizados testes com distâncias superiores a 200 metros pois nessa distância ocorriam perdas de pacotes na comunicação. Este teste demonstra que o protocolo XBee não é adequado para ser utilizado como protocolo de telemetria. Porém, pode ser utilizado para captar os dados após o pouso do foguete, facilitando a sua localização.

5.3.3 Telemetria. Para a telemetria, conforme já descrito, foram utilizados sensores de pressão atmosférica, temperatura, umidade e localização. Os testes foram realizados apenas em bancada verificando se os dados coletados estavam de acordo com os dados provenientes de outras fontes.

\section{CONSIDERAÇÕES FINAIS}

Este trabalho apresentou o desenvolvimento de um foguete de baixa altitude para ser utilizado como meio de auxiliar o ensino. Por ser desenvolvido por estudantes de ensino médio que não possuem contato com a área espacial, o desenvolvimento desse trabalho permitiu que estes estudantes aplicassem diversos conceitos vistos apenas em sala de aula. Como o objetivo do foguete é auxiliar no ensino, o fato desses alunos aplicarem os conhecimentos, já pode ser entendido como objetivo atendido.

A proposta desse foguete é ser demonstrado e replicado por equipes e alunos que tenham interesse. No entanto, devido às restrições impostas para tentar combater o Covid-19, não foram realizados lançamentos com esse foguete.

\section{ACKNOWLEDGMENTS}

Projeto financiado pelo EDITAL N $42 / 2019$ - PROPPI/IFSC/GASPAR Programa de Apoio ao Fortalecimento de Grupos de Pesquisa e Núcleos de Atividades do Câmpus Gaspar e; EDITAL 02/2020/PROPPI/IFSC Universal de Pesquisa.

\section{REFERÊNCIAS}

[1] André L. D. GONÇALVES. Sonda chinesa inicia volta à terra trazendo $2 \mathrm{~kg}$ de solo da lua, 2020. URL https://www.tecmundo.com.br/ciencia/207764-sonda-chinesainicia-volta-terra-trazendo-2-kg-solo-lua.htm.

[2] André L. D. GONÇALVES. Rússia planeja retomar o envio de missões de exploração a vênus, 2020. URL https://www.tecmundo.com.br/ciencia/177946-russia-planejaretomar-envio-missoes-exploracao-venus.htm.

[3] OBA Olimpíada Brasileira de Astronomia. O que é a mobfog, 2020. URL http://www.oba.org.br/site/?p=conteudo\&pag=conteudo\&idconteudo=586\& idcat $=29 \&$ subcat $=$.

[4] BAR/ABMf. Vii festival brasileiro de minifoguetes, 2020. URL https://andiogenes. wixsite.com/viifestival.

[5] Latin American Space Challenge. What is lasc?, 2020. URL http://lasc.space/whatis-lasc/.

[6] Luiz E. M. J. RODRIGUES. Fundamentos da Engenharia Aeronáutica com Aplicações ao Projeto SAE-AeroDesign: Volume Único. 2014. ISBN 978-85-918113-2-8. www. engbrasil.eng.br.

[7] Pedro H. O. GOMES. Concepção de sistema de telemetria para aeronaves remotamente controladas, 2016. TCC (Graduação) - Curso de Engenharia de Controle e Automação, Colegiado do Curso de Engenharia de Controle e Automação, Universidade Federal de Ouro Preto, Ouro Preto.

[8] Yuri CROTTI. Avaliação de desempenho de protocolos de transmissão para redes de sensores sem fio aplicadas à agricultura, 2017. TCC(graduação) - Universidade Federal de Santa Catarina. Campus Araranguá. Engenharia de Computação. Araranguá.

[9] Francisco J. F. CARANDE. Motor foguete de combustível sólido, 2011. Dissertação (Mestrado) - Engenharia Aeronáutica. Universidade da Beira Interior. Covilhã. 